\title{
FungalRoot: global online database of plant mycorrhizal associations
}

\author{
Nadejda A. Soudzilovskaia ${ }^{1 \dagger}$ (D), Stijn Vaessen ${ }^{1 *}$ (D), Milagros Barcelo ${ }^{1 *}$ (D), Jinhong He $^{2}$, Saleh Rahimlou ${ }^{3}$ (D), Kessy \\ Abarenkov $^{3}$ (D), Mark C. Brundrett ${ }^{4}$ (D), Sofia I.F. Gomes ${ }^{1}$ (D), Vincent Merckx ${ }^{5,6}$ (D) and Leho Tedersoo ${ }^{3 \dagger}$ (D) \\ ${ }^{1}$ Environmental Biology Department, Institute of Environmental Sciences, CML, Leiden University, Einsteinweg 2, 2333 CC, Leiden, the Netherlands; ${ }^{2}$ South China Botanical Garden, \\ Chinese Academy of Sciences, No.723 Xingke Road, Tianhe District, 510650 Guangzhou, China; ${ }^{3}$ Institute of Ecology and Earth Sciences, University of Tartu, Ülikooli 18, 50090 Tartu, \\ Estonia; ${ }^{4}$ School of Biological Sciences, Faculty of Science, University of Western Australia, 35 Stirling Highway, Perth, WA 6009, Australia; ${ }^{5}$ Understanding Evolution Group, Naturalis

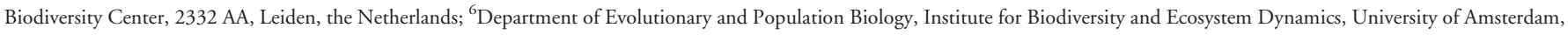 \\ 1098 XH,Amsterdam, the Netherlands
}

Authors for correspondence:

Nadejda Soudzilovskaia

Tel: +31 (0)715277485

Email:n.a.soudzilovskaia@cml.leidenuniv.nl

Leho Tedersoo

$\mathrm{Tel}+3727375651$

Email: leho.tedersoo@ut.ee

Received: 29 July 2019

Accepted: 10 March 2020

New Phytologist (2020) 227: 955-966

doi: 10.1111/nph.16569

Key words: arbuscular mycorrhiza (AM), biogeography, ectomycorrhizal (EcM), ericoid mycorrhiza (ErM), mycorrhizal root colonization, mycorrhizal type,

nonmycorrhizal plants, orchid mycorrhiza (OM).

\section{Introduction}

Mycorrhizal interactions with fungi represent one of the key innovations of terrestrial plants. A mycorrhiza is a mutualistic association between plant roots and fungi, where plants provide photosynthetically derived carbohydrates to fungi, and fungi deliver nutrients and water to plants and offer protection from abiotic and biotic stress (Smith \& Read, 2008). Based on anatomy and partners' identity, four principal types of mycorrhiza are recognized: arbuscular mycorrhiza (AM), ectomycorrhizal (EcM), ericoid mycorrhiza (ErM) and orchid mycorrhiza (OM) (Brundrett \& Tedersoo, 2018). Although most vascular plant species form mycorrhizal symbiosis of only one type, AMcolonized roots are sometimes also co-colonized by EcM and

${ }^{*} \uparrow$ These authors contributed equally to this work.
ErM fungi (Smith \& Read, 2008; Brundrett \& Tedersoo, 2018). Many EcM fungi can form typical orchid mycorrhizal associations with mycoheterotrophic orchids (Imhof et al., 2013). EcM and ErM fungi also may grow endophytically in roots of other plants without forming any mycorrhiza-like structures (Kohout, 2017; Schneider-Maunoury et al., 2020).

Depending on mycorrhizal types and particular species, mycorrhizal fungi may build extensive mycelial networks that sustain nutrient acquisition and promote plant seedling establishment (Leake et al., 2004). Mycorrhizal types differ in their influence on plant nutrition and therefore affect plant carbon allocation strategies (Veresoglou et al., 2012b), litter quality (Cornelissen et al. (2001) cf. Koele et al. (2012), and decomposition (Cornelissen et al., 2001; Elumeeva et al., 2018), biogeochemical cycles (Veresoglou et al., 2012a; Soudzilovskaia et al., 2015a; Averill \& Hawkes, 2016; Tedersoo \& Bahram, 2019) and plant 
community composition (van der Heijden et al., 1998; Klironomos et al., 2000; Klironomos et al., 2011; Elumeeva et al., 2018). Information about mycorrhizal tratits and colonization intensity of mycorrhizal infection of plant roots is crucial for understanding plant and fungal effects on ecosystem-level and global biogeochemical processes (Phillips et al., 2013; Soudzilovskaia et al., 2015a; Terrer et al., 2016; Tedersoo et al., 2019).

Plants also differ in the level of root colonization intensity by mycorrhizal fungi, which may have an effect on the efficiency of nutrient uptake (Karst et al., 2008; Hoeksema et al., 2010; Treseder, 2013) or protection against pathogens (Smith \& Read, 2008). Much of the variation in colonization intensity seems to be related not only to plant and fungal identity, but also to seasonality and environmental conditions (Klironomos, 2000; Maltz \& Treseder, 2015; Hoeksema et al., 2018). Furthermore, data about root colonization by mycorrhizal fungi provides insights into the level of intimacy of the plant-fungal interactions, linked to plant nutrition effectiveness and environmental drivers of plant communities (Soudzilovskaia et al., 2015b). Some plant species - so-called 'facultatively mycorrhizal plants' - may develop mycorrhizas in certain conditions but remain nonmycorrhizal in other conditions, depending on nutrient availability and neighbouring plants (Brundrett, 2017).

However, the type and intensity of root colonization by mycorrhizal fungi is unknown for the great majority of vascular plants and, when available, this information is scattered among multiple narrow-focused datasets, most of which cover specific geographical regions or mycorrhizal types. Sources of mycorrhizal records contain multiple errors, which have accumulated and passed on through literature reviews. Many of these errors are derived from alternative interpretations of mycorrhiza and mycorrhizal types, which are especially common in old literature (Brundrett $\&$ Tedersoo, 2019; Bueno et al., 2019). Unfortunately, these incorrect observations have been commonly used in traits-based case studies or meta-analyses without critical evaluation of the source reliability, which may have caused errors in interpretation and conclusions (Tedersoo et al., 2019). Furthermore, most data compilations lack geographical information and environmental metadata about the study sites. A substantial part of fundamental mycorrhizal research has been published in languages other than English, German or French, and thus has remained overlooked in reviews and datasets. Finally, virtually none of the existing data compilations distinguish between research focused on all mycorrhizal types detected for a particular plant species and specific mycorrhizal types (ignoring other types that may be present in the specimen, and therewith assigning a particular mycorrhizal type to the plant species under scrutiny, whereas that species might in reality feature double mycorrhizal colonization types).

Here, we present a global database FungalRoot, which accumulates information about plant mycorrhizal status and root colonization intensity. The FungalRoot database was assembled based on local databases and a large number of case studies as well as recent studies published in nine widespread languages. The database enables users to distinguish between reports of a presence of a particular mycorrhizal type, and reports where the plants were checked for all existing mycorrhizal types. In addition, our database provides information about the locality, ecosystem type, soil chemical data and the method of mycorrhizal assessment, enabling users to build more specific, local reference databases. FungalRoot offers possibilities to provide curator and third-party expert opinion regarding data reliability. Based on the current version of the database we provide a genus-level recommendation list for mycorrhizal type assignment of vascular plants, based on data quality, habitat information and phylogenetic relationships (Brundrett \& Tedersoo, 2018), Supporting Information Table S2. These data considerably advance the previously available major check list of plant mycorrhizal status (Wang \& Qiu, 2006; Akhmetzhanova et al., 2012) both in number of plant taxa considered, as well as in the accuracy of mycorrhizal trait diagnoses, because previous lists potentially contain many unmanaged errors (Brundrett \& Tedersoo, 2019). We recommend using the corrected (genus-level) list of the mycorrhizal traits in comparative studies and meta-analyses, in cases where plant mycorrhizal types were not empirically determined, and when species-level information could not be found in the FungalRoot database.

\section{Materials and Methods}

\section{Literature compilation}

We combined data from 1775 sources of literature, including articles obtained through Google Scholar searches, large compilations of information on mycorrhizal colonization type and intensity in plants (Harley \& Harley, 1987; Wang \& Qiu, 2006; Akhmetzhanova et al., 2012; Hempel et al., 2013; Soudzilovskaia, et al., 2015b; Gerz et al., 2016), and the authors' personal literature collections, as well as unpublished data. For the Google Scholar search, we used a boolean search for 'mycorrhiza' AND 'colonisation' AND 'name of each country' in English and in other major languages (including German, Chinese, Farsi, French, Indonesian, Portuguese, Russian, Spanish). The articles were downloaded from the Internet, acquired from the authors or ordered using interlibrary loans. We focused mainly on papers with observations on at least five species or $>10$ observations for a lower number of species separable by space or specific treatments. Observations in data compilations were traced back to the original references in order to add geographical and ecological metadata, check for methods and avoid transferring errors.

Presence of mycorrhizal status information of a plant species or genus was the minimum requirement to include observations in the database. In cases when the data on root colonization intensity by specific mycorrhizal types were reported, we included these data as well along with the information about a method used for colonization assessment. All collected references were carefully checked for information about geographical location, environmental conditions and habitat (see Supporting Information Table S1 for the lists of included variables and character states).

Data about site soil conditions were added to each record when available. Nitrate $\left(\mathrm{NO}_{3}{ }^{-}\right)$or ammonium $\left(\mathrm{NH}_{4}^{+}\right)$values were converted to $\mathrm{N}$ based on atomic mass (e.g. $\mathrm{X} \mathrm{mg} \mathrm{NO}_{3}{ }^{-}$) 
$\mathrm{kg}=\mathrm{X} \times 14 / 62 \mathrm{mg} \mathrm{N} \mathrm{kg}^{-1}$, as the atomic mass ratio between $\mathrm{N}$ and $\mathrm{NO}_{3}{ }^{-}$is $14: 62$. Likewise for $\mathrm{NH}_{4}^{+}$with atomic mass ratio of $14: 18$ between $\mathrm{N}$ and $\mathrm{NH}_{4}{ }^{+}$. Minimum and maximum values, or ranges, were included if available.

\section{Assessment of mycorrhizal types}

We followed the mycorrhiza definitions of Brundrett $\&$ Tedersoo (2018) that largely relied on Brundrett (2009). Because the associated fungi were rarely identified and their benefits to plants were not assessed in studies addressing mycorrhizal status or level of colonization of natural plants, in most cases we relied solely on the literature-reported morphological criteria (except Australian studies in 1980s and early 1990s that involved synthesis experiments). In brief, the presence of intracellular arbuscules, coils or pelotons was required to consider plants arbuscular mycorrhiza $(\mathrm{AM})$, ericoid mycorrhiza (ErM) or orchid mycorrhiza $(\mathrm{OM})$, respectively. For ectomycorrhizal (EcM), the presence of a Hartig net or a well-developed mantle (one or more hyphal layer) was required. Recently, Bueno et al. (2019) argued that arbuscular colonization is not required for functional AM symbiosis, and presence of other fungal structures, such as vesicles, could be considered as a diagnostic feature. However, the current version the FungalRoot is limited to the data corresponding to the mycorrhizal definitions of Brundrett \& Tedersoo (2018). But the database is open to adding new definitions of mycorrhizas, and references based thereon; see below and in the S1 how to add new data to the database.

Misdiagnoses of mycorrhizal types are a common problem in scientific literature (Brundrett, 2017; Tedersoo \& Brundrett, 2017; Brundrett \& Tedersoo, 2019) and these could lead to errors in analyses based on uncritical use of literature compilations. We considered it important to report the original diagnosis of mycorrhizal type provided in the original publication. Simultaneously, we examined each record in our database against contemporary knowledge of plant species mycorrhizal types (consensus of records in this study; specific information in Merckx, 2013; Kohout, 2017; Tedersoo \& Brundrett, 2017; Brundrett \& Tedersoo, 2018, 2019). Based on this examination, in the current version of the database, we provide up to three expert opinions commenting on the reliability of the original diagnosis for each contradictory record (see subsection 'Data records' below). The dynamic setup of the database allows for the addition of more expert opinions. Based on the database records and the expert opinions, we prepared a recommendation list of mycorrhizal status at the plant genus level (Table S2). To compile this dataset, we considered individual studies of low reliability and excluded these from further comparisons if $>20 \%$ of records therein conflicted with other studies. We anticipate, however, that differences in nonmycorrhizal (NM) and AM habit may exist, especially in facultatively mycorrhizal plants and seasonally, depending also on age, environmental conditions and criteria used to assign mycorrhizal types (Brundrett \& Tedersoo, 2019; Bueno et al., 2019). The records excluded during the compilation process of the recommendation list were still kept in the database.
Based on individual reports for species, we assigned mycorrhizal type or NM status to the entire genus if $>67 \%$ of reports (at least two observations) converged. The value of $67 \%$ was chosen because with an expectation of $100 \%$ consistency among the reports, the results in nearly all plant genera hosting arbuscular and ectomycorrhizal plants fall into the categories of EcM-AM or AM-NM. Besides the fact that such outcome is trivial, it also is misleading because of a considerable chance for at least some misdiagnosis cases. Therefore, we have opted a threshold of $2 / 3$ of the observations (i.e. 67\%) being consistent. The value of $2 / 3$ $(67 \%)$ was chosen arbitrarily, but is supported by the fact that in cases of detailed laboratory assessments being available for individual plant species, their conclusions are in the majority of cases consistent with c. $60-75 \%$ of observations presented in the FungalRoot database. In putatively AM and NM groups, there were multiple genera that were reported to be either AM or NM in $33-67 \%$ of occasions. These facultatively arbuscular mycorrhizal taxa were encoded as AM-NM. In predominantly AM and EcM plant families, we considered a single positive report sufficient to consider the genus mycorrhizal. If there was a single NM report in these mycorrhizal families, the mycorrhizal status was considered unsettled, rather than prematurely nonmutualistic or unreliable, as recommended by Harley \& Harley (1987). For genera that had no reports or single negative reports or two conflicting reports, we further relied on the list of putative NM plant families (Brundrett \& Tedersoo, 2018) and EcM plant genera (Tedersoo, 2017), and studies considered unreliable in the first phase. Several aquatic and heterotrophic plant genera in the putatively NM plant families were considered as AM-NM because of multiple independent evidence for arbuscule formation. Given that the assignments of genus-level mycorrhizal type were conducted at $67 \%$ level of consistency, there was an obvious possibility for a mismatch in mycorrhizal types of individual species (e.g. Sun et al., 2019). Thus, the data presented in the Table S2 should, as such, never be used to detect misdiagnoses. Rather they should be used in ecological analyses in cases where more detailed information is not available. However we plead for great caution in the use of these assignments and an adequate accounting for error propagation, when using these data.

According to our data compilation, 86 plant families lack information about mycorrhizal types (Table S3). Following Brundrett \& Tedersoo (2018), we considered that Brassicales, Caryophyllales and Cyperales included multiple families with mostly NM or AM-NM species. In Brassicales, we relied partly on the distribution of mycorrhiza-related genes (Delaux et al., 2014). If such information was missing (Brassicales) and for other putatively AM-NM orders, we considered the mycorrhizal status of unstudied families unsettled. For orders that contain only AM genera, we considered unsampled families as putatively AM. We also included specific comments on species of EcM plants that have a larger group of congeneric AM species (Pisonia, Persicaria, Kobresia). For Australian Fabaceae, Goodeniaceae, Myrtaceae and Asteraceae, this was unfeasible because insufficient information. We identified only a single consistently NM plant species Astragalus alpinus within a mycorrhizal genus. 


\section{Technical validation}

For correction and standardization of the species names included in the database, all observations were checked using the Taxonomic Name Resolution Service (TNRS) (http://nns.iplantcol laborative.org/). When partial matches were found, species names were corrected manually according to the best suggestion given by the TNRS. When no suggestions were given, the species name was checked in the original papers. If the species name could still not be corroborated, the record was removed, or, when possible, treated at the level of genus. The species names originally reported in the papers can be obtained from the authors upon request.

\section{Data records}

The data are organized into five categories: (1) observation identification; (2) location; (3) soil conditions; (4) host plant description; and (5) description of mycorrhizal colonization (Table S1). The fields for literature references refer to one particular study and include 'publication_doi' (for a Digital Object Identifier, DOI, of the citation) and 'original_reference' (full text citation in GoogleScholar APA format, necessary for older literature with no DOI or other alphabet). Chinese, Japanese, Persian, Arabic, Cyrillic and other alphabets also conform to this field, although sources in these languages (except Chinese) have been converted or translated to the main format during data management or within previous reviews for simplicity. The field 'plot_name' enables segregation of the study into smaller units by location but also by time, treatment or any custom difference. It is represented by the name of the locality or locality-by-treatment combination. All records within a plot have the same geographical coordinates. Identical plot names in different studies are not matched unless their coordinates match.

For the location category, 'habitat naturality' enables selection amongst eight possibilities (plus 'other' if none conform) that are related to the experimental conditions or habitat structure; 'biome' provides information about the overall climate and vegetation type; 'country' represents a user-selected field for countries (autonomous and overseas regions separately) following MIMARKS standards; 'latitude' and 'longitude' represent geographical coordinates, whereas 'elevation' represents altitude; 'collection_date' indicates date of observation.

In order to enable in-depth meta-analyses, we included 12 fields for soil chemical parameters that are commonly reported in mycorrhiza literature, along with the description of methods for their assessments. The fields 'pH', 'pH_min', 'pH_max', ' $\mathrm{pH}$ _range' and 'pH_method' denote the value and measurement method for determination of soil $\mathrm{pH}$. The fields 'total_organic_carbon' and 'total_organic_carbon_method' are used to state the value ( $\mathrm{g} / \mathrm{kg}$ soil) and determination method for soil organic carbon content. Likewise, 'total_nitrogen', 'total_extractable_nitrogen' and 'total_nitrogen_method' indicate the value $\left(\mathrm{g} \mathrm{kg}^{-1}\right)$ and method of determination for total soil nitrogen. The fields 'total_phosphorus', 'total_available_phosphorus' and 'total_available_phosphorus_method' indicate concentration of total phosphorus ( $\mathrm{mg} \mathrm{kg}^{-1}$ soil; method) or available phosphorus ( $\mathrm{mg} \mathrm{kg}^{-1}$ soil) and its method of measurement. 'Potassium', 'calcium' and 'magnesium' represent fields for $\mathrm{K}, \mathrm{Ca}$ and $\mathrm{Mg}$ concentrations ( $\mathrm{mg} \mathrm{kg}^{-1}$ soil; method).

There are three fields for plant species. One of the most important fields is 'species', which represents the taxon studied. If no epithet is given, the taxon is identified to genus level. The field 'number_of_individuals_studied' represents the sample size of the original study: the total number of individuals of a given species assessed in the given study to establish a mycorrhizal type and/or level of colonization. The 'host_age' represents a selectable field of the age of particular individuals, ranging from $<1$ month to $>10 \mathrm{yr}$.

Information about mycorrhizal type and colonization intensity and frequency are given in a suite of 13 fields due to data complexity. The field 'mycorrhiza_type' is a selection of 15 options indicating combinations from single mycorrhiza types to dual mycorrhizal colonization, including specification of whether other types have been addressed or not. We find these possibilities important to be considered in scientific analyses, as they allow more reliable negative results to be distinguished from negative reports that may be derived due to the lack of survey for other mycorrhiza types besides the focal AM or EcM. This field also includes suggestions for mycorrhiza-like associations in rootless plants, such as hepatics (levels 'AM-like', 'EcM-like', 'ErM-like' and 'OrM-like'). The fields 'AM_intensity' and 'AM_frequency' indicate relative intensity (an estimate of colonization abundance within a root system, determined by one of the methods described in the 'methods' field) and frequency (\% of plant individuals colonized), respectively. Analogous fields exist for EcM, ErM and OM. The field 'AM_method' enables 17 options to indicate the method and scale for determination of AM, whereas 'EcM_method', 'ErM_method' and 'OM_method' offer 10, seven and seven options, respectively.

The FungalRoot database contains six remarks fields. The 'remark_mycorrhiza_type' represents notes on reported mycorrhiza type or colonization determination method. Specially dedicated fields enable expert opinions about mycorrhizal type of each observation reported in the database. The fields contain name of the expert and the expert comment, so all expert opinions can be sorted with the data. The downloaded data could be sorted based on presence/absence of expert opinions. The expert opinion fields warn users against possible suspects for mycorrhizal type mis-assignments, which are common in the literature, while allowing the data reported by the original publication to be stored in the database. The current version of the database contains remarks of three experts: Leho Tedersoo, Mark Brundrett and Laura Martinez-Suz. However, the dynamic set-up of our database allows continuous data additions and editing, with a possibility to add new comments by external experts. We welcome scientists to collaborate by providing their expert opinion on the reliability of the database records.

The field 'other_remarks' provides additional information about methods, specific experimental treatments and other approaches used in each particular paper. Ecological and evolutionary analyses may be sensitive to such data. 
(a) Arbuscular mycorrhizal colonization

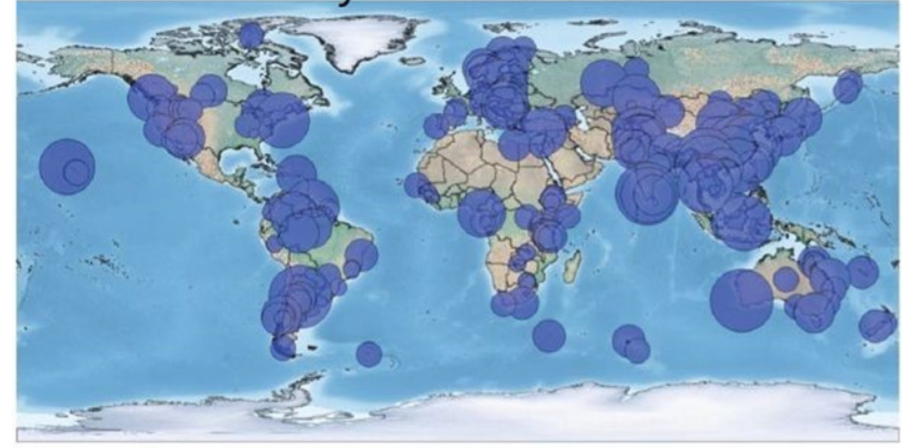

Number of records per location

(c) Ericoid mycorrhizal colonization

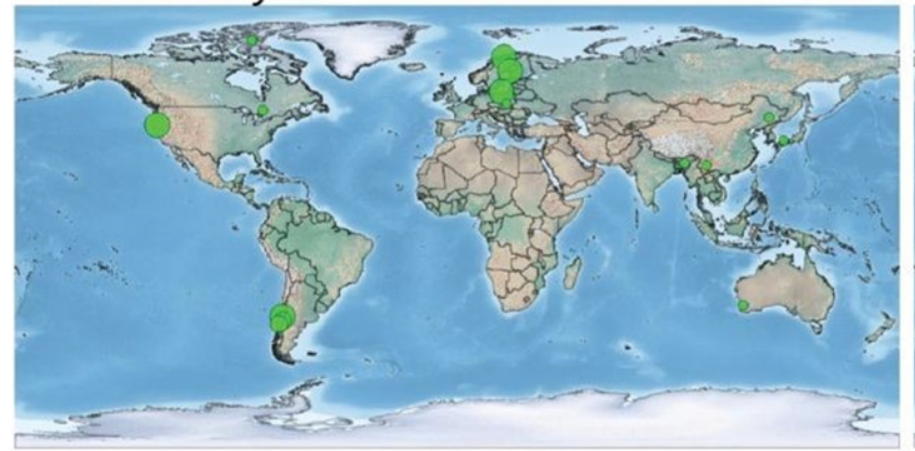

(b) Ectomycorrrhizal colonization

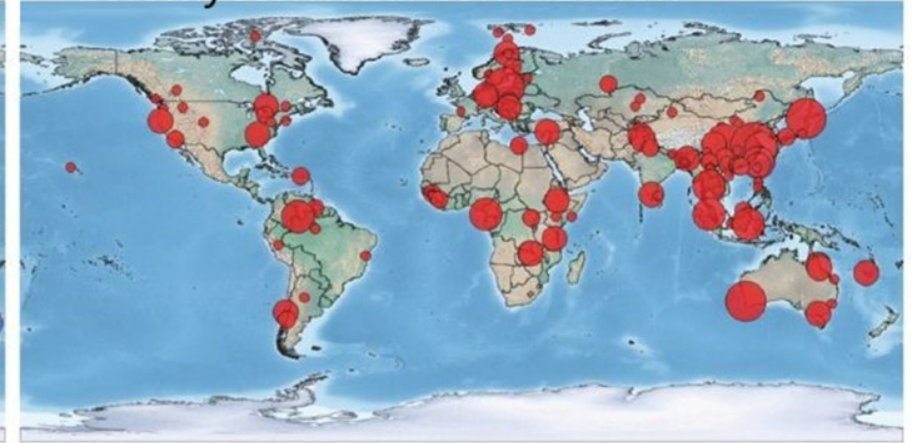

(d) Nonmycorrhizal plants

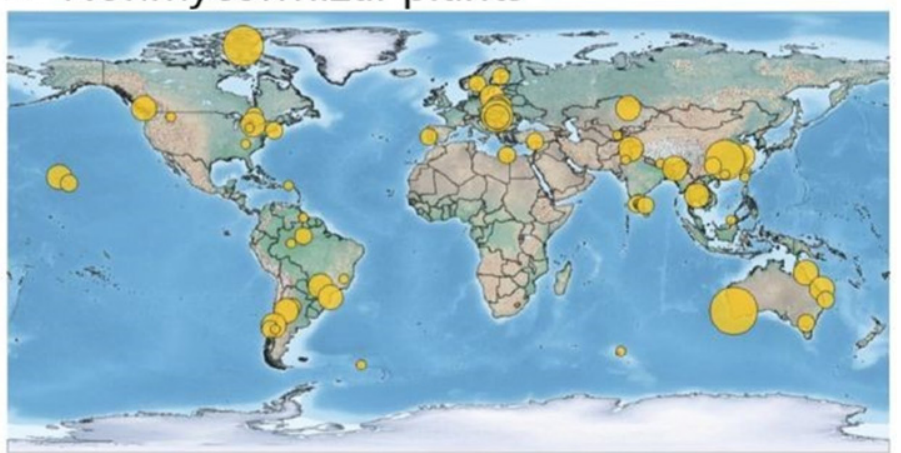

Fig. 1 Georeferenced records included in the FungalRoot database by colonization: (a) arbuscular mycorrhizal (AM), (b) ectomycorrhizal (EcM), (c) ericoid mycorrhizal (ErM) and (d) nonmycorrhizal (NM). Circle size reflects number of observations per site.

In order to facilitate ease-of-use of the data and to enable efficient updating and versioning, the currently published version of the FungalRoot database is integrated within the online data management and publishing platform PlutoF (Abarenkov et al., 2010b). This structure enables management and editing of multiple fields, custom search by any field, and third-party annotations, such as comments or specification of missing details.

\section{Results}

\section{FungalRoot database structure}

Our data are freely available for the scientific community, upon citation of this manuscript. They are accessible through the PlutoF platform (https://plutof.ut.ee) for authenticated users, who also have the possibility to add new data and comment the existing data. Additionally the current version of the database is published through GBIF (https://www.gbif.org/dataset/744edc $21-8 \mathrm{dd} 2-474 \mathrm{e}-8 \mathrm{a} 0 \mathrm{~b}-\mathrm{b} 8 \mathrm{c} 3 \mathrm{~d} 56 \mathrm{a} 3 \mathrm{c} 2 \mathrm{~d})$. When uploading the data to the PlutoF, the names were converted to the GBIF backbone taxonomy. Each new version of the data published on the PlutoF platform will be linked to the GBIF version of the database. Notes $S 1$ provides detailed information on how to become a user of PlutoF. For versioning of the database we recommend referral to the DOI assigned to the data through GBIF system. All PlutoF platform users can join the PlutoF 'Mycorrhiza Intensity' workgroup and link new data records to the 'Mycorrhiza Intensity project'. We invite experts to add new records to the database and to provide comments on the reliability of existing records, in terms of assignment of mycorrhizal types and other issues. We also invite users to add alternative definitions of mycorrhizal types, provided that records based on alternative definitions will be indicted as such. The database additions submitted will be regularly (e.g. monthly) processed by the PlutoF administrators and added to the database.

For data input, there are two principal ways: (1) using an upload file in a spreadsheet format or (2) direct data insertion over the web platform, which is analogous to the UNITE database system (Abarenkov et al., 2010a). Both the online data insertion and upload file contain the same data fields supplied with specific information. Some fields contain free text, whereas others enable a selection menu to secure consistent terminology. The scientific terminology generally follows MIMARKS standards that were supplemented with more detailed terms (such as mycorrhiza types and specific methods).

\section{Mycorrhizal data}

In total, our database contains 36303 observations for 14870 plant species. A total of 19893 observations included in the database are linked to geographical coordinates (Fig. 1).

Among the total number of observations, $45 \%$ and $2.5 \%$ include information about the intensity and frequency of mycorrhizal colonization, respectively. Of mycorrhiza types, studies 
(a) Number of records per mycorrhizal type

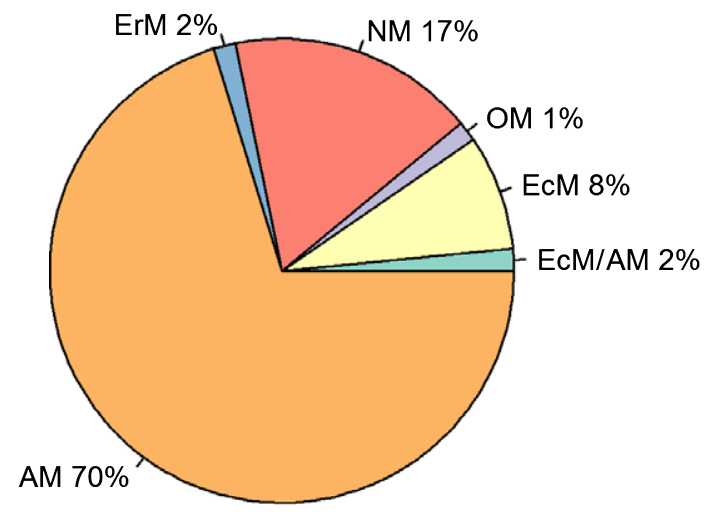

(c) Number of records per major biome type

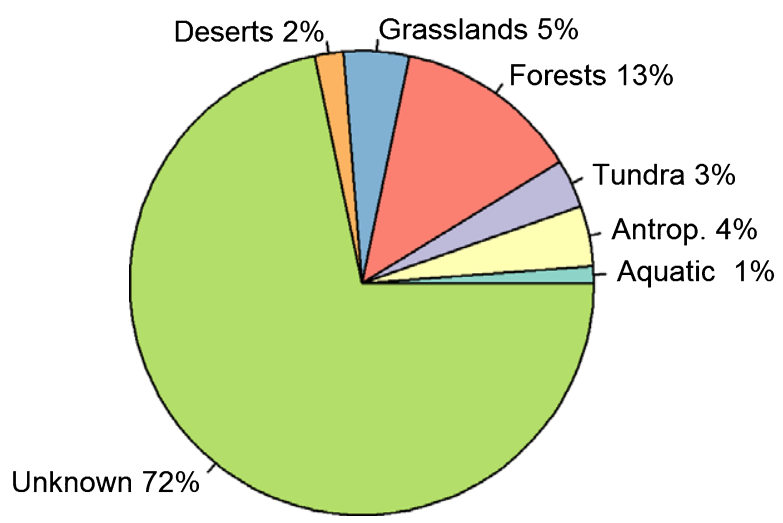

\section{(b) Number of records per habitat type}

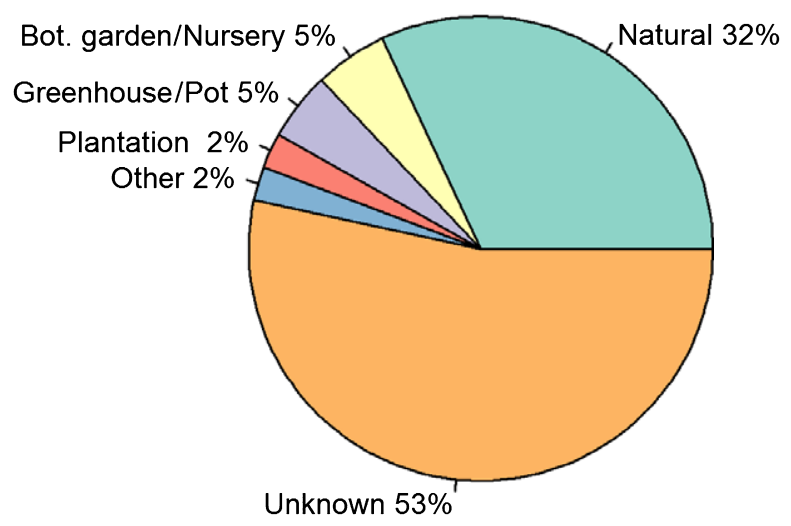

(d) Number of records per country

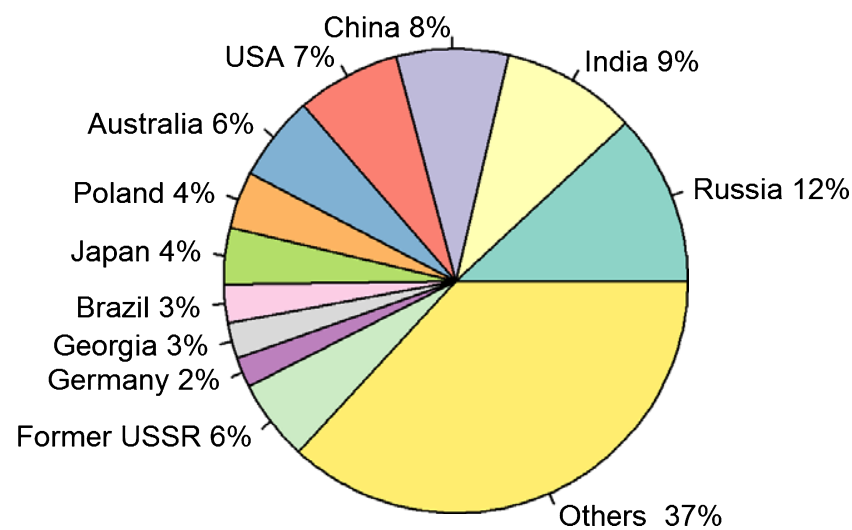

Fig. 2 Number of records in the FungalRoot database (a) per most common mycorrhizal type, (b) per habitat type, (c) per major biome type and (d) per country. In (a) the EcM-AM category refers to cases of mixed colonization by the two types of mycorrhizal fungi. The numbers of records for the types 'ErM-AM', 'ErM-EcM', 'AM-like (nonvascular plants)', 'EcM-like (nonvascular plants)', 'ErM-like (nonvascular plants)' and 'OM-like (nonvascular plants)' are $9,14,8,22,0$ and 0 , respectively. Owing to the small values these categories are not shown in the graph. In (c) the biome 'Aquatic' includes mangroves; 'Anthrop.' stands for 'Anthropogenic'. In (d) the category 'Former USSR' refers to the records originated from the dataset of Akhmetzhanova et al. (2012), that are not assigned to Russia, but are assigned to other republics of USSR (now independent countries). Colonization types: AM, arbuscular mycorrhizal; EcM, ectomycorrhizal; ErM, ericoid mycorrhizal; OM, orchid mycorrhizal.

and observations about putatively AM plants prevail, followed by observations on EcM plants and NM plants (Fig. 2a). Among recorded habitats where mycorrhizal plants have been assessed, natural habitats prevail, being mostly forests and grasslands (Fig. 2b,c). Records are unequally distributed among plant species. Only $0.2 \%$ of the species had $>40$ records (Fig. S1). A large number of species (59\%) had only one record, whereas $18 \%$ and $8 \%$ of species had two and three records, respectively.

Observations about mycorrhizal status were distributed unequally globally, with greatest density in North Europe and North America, and lowest density in Africa, Central Asia and Oceania (Fig. 1). This is related directly to historical and present development of mycorrhiza research in different regions. We found literature about mycorrhizal status of plants in nine languages that fitted our criteria for inclusion. Relevant literature in English language clearly dominated, followed by Chinese, Spanish, Portuguese, Russian and French. Among countries, Russia, India, China and USA are best represented (Fig. 2d).
Patterns in the colonization level data are presented in Fig. 3. For the majority of plant species featuring AM infection, the database contains information about AM colonization intensity (Fig. 3a,b,). Likewise, for c. 65\% of plant species featuring EcM infection and examined for all type of mycorrhiza, and for $49 \%$ of plants featuring ErM infection our database contains information about colonization intensity (Fig. 3,d,f). Colonization intensity information for plant species featuring both AM and EcM infection, for species featuring EcM infection but not examined for other types of mycorrhiza, and for species featuring $\mathrm{OM}$ infection is scarce (Fig. 3c,e,f).

In order to examine how distinct mycorrhizal types are distributed across plant growth forms (trees, herbs, shrubs), we extracted the publicly available data from TRY (https://www.trydb.org/) (Kattge et al., 2011). In this analysis, we considered the mycorrhizal type to correspond to that in the original report. Among obligate AM plant species, 50\% are herbaceous, $25 \%$ are trees, $10 \%$ are shrubs and the remaining $15 \%$ plant species are 
(a) AM only, all other types addressed (3947 records)

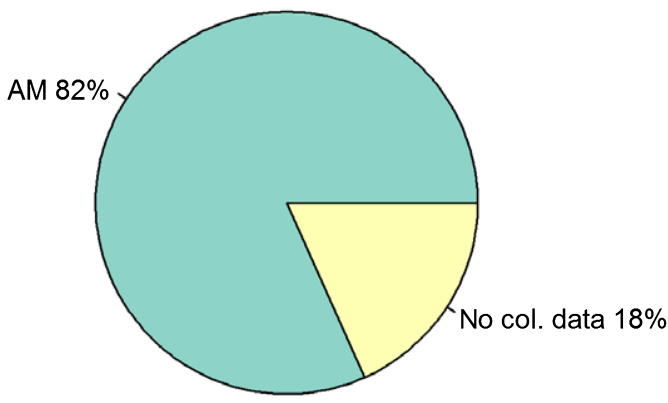

(c) Colonization by EcM and AM (586 records)

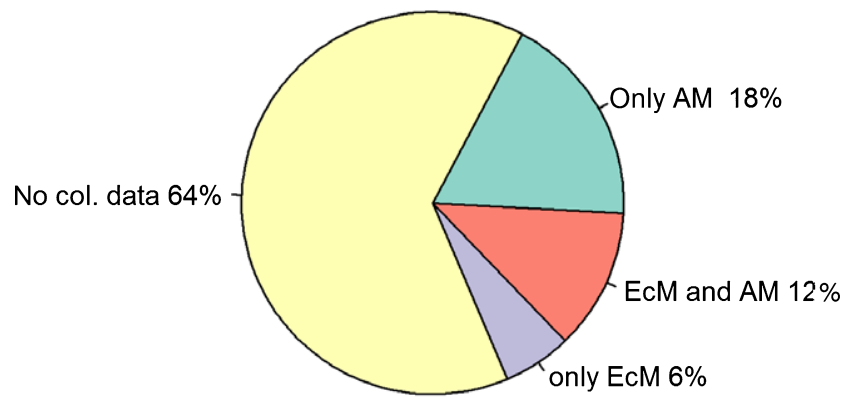

(e) EcM, other types not addressed (2773 records)

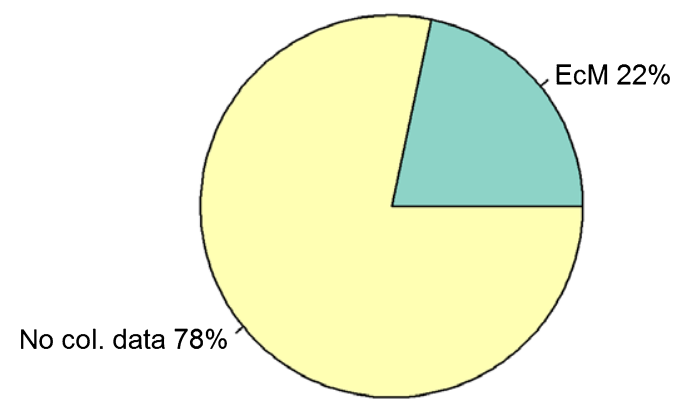

(g) OM (473 records)

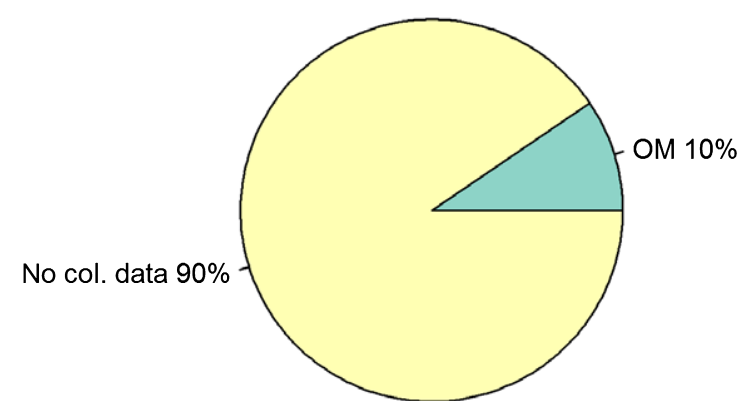

(b) AM, other types not addressed (17236 records)

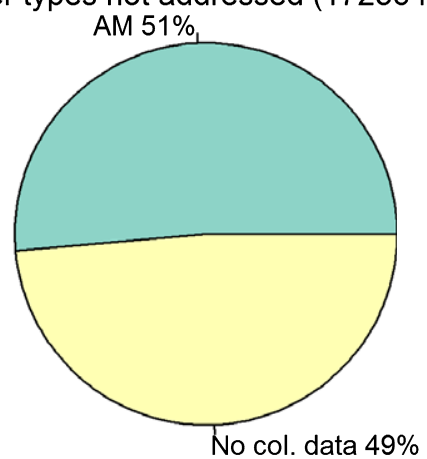

(d) EcM only, all other types addressed (2605 records)

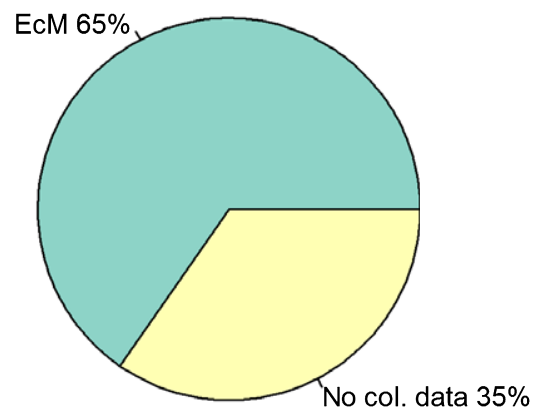

(f) $\operatorname{ErM~(319~records)~}$

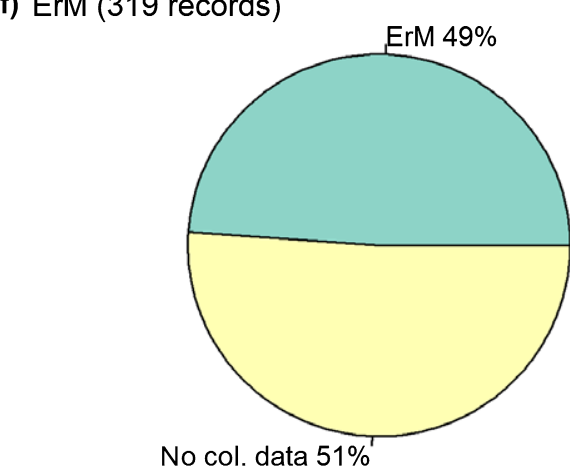

Fig. 3 Patterns of the colonization-level data showing number and percentage of species for which information about colonization level is available. (a) AM-only colonization, all other types of mycorrhizal colonization addressed. (b) AM-only colonization, all other types of mycorrhizal colonization not addressed. (c) Double colonization by EcM and AM mycorrhizal fungi. (d) EcM-only colonization, all other types of mycorrhizal colonization addressed. (e) EcM-only colonization, all other types of mycorrhizal colonization not addressed. (f) ErM colonization. (g) OM colonization. Colonization types: AM, arbuscular mycorrhizal; EcM, ectomycorrhizal; ErM, ericoid mycorrhizal; OM, orchid mycorrhizal. 
(a) Obligatory AM species

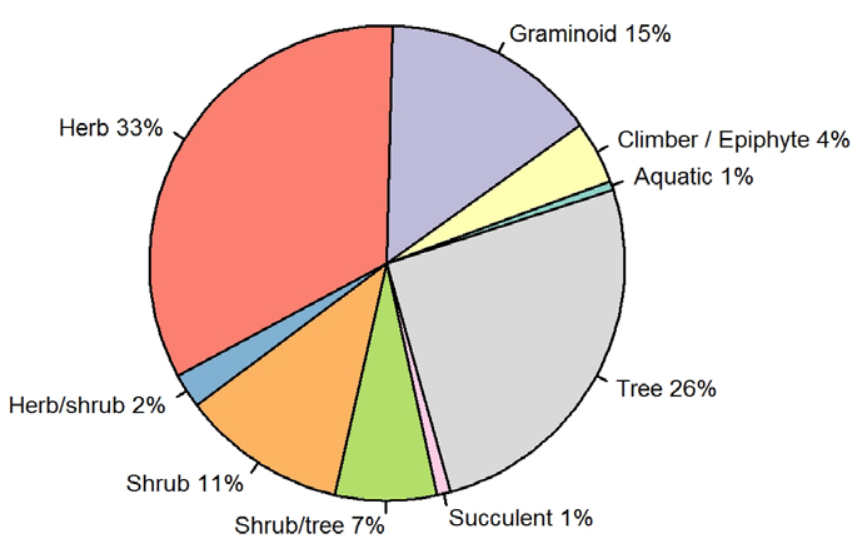

(c) EcM-AM species

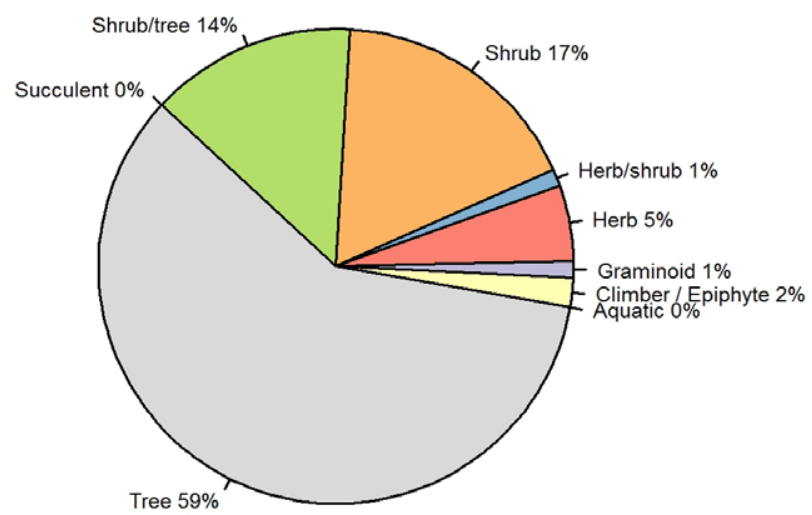

(e) ErM species

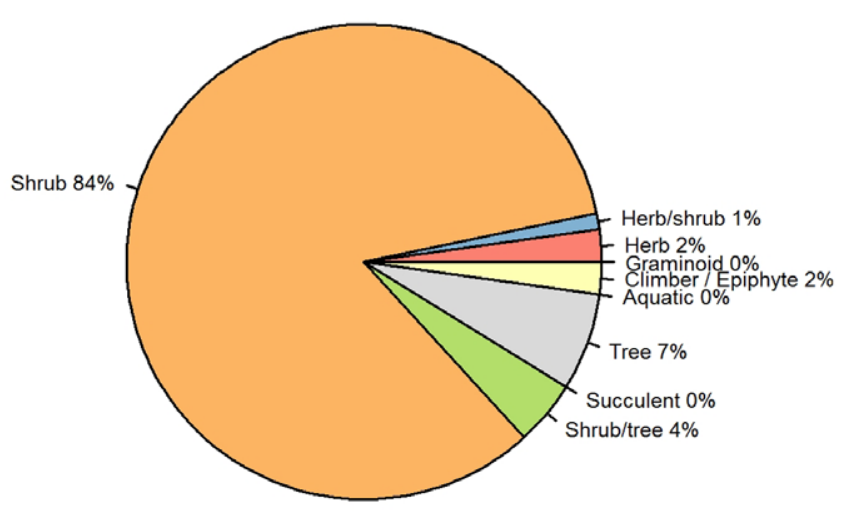

(b) Facultative AM species

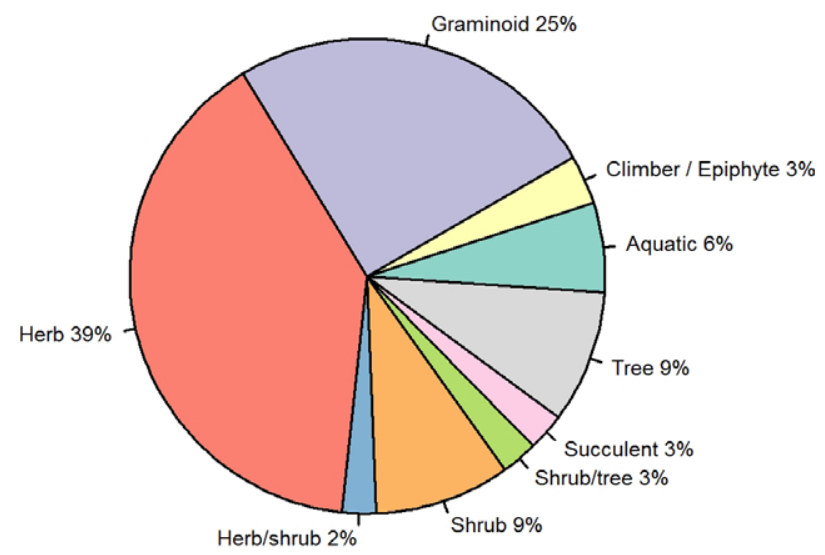

(d) EcM species

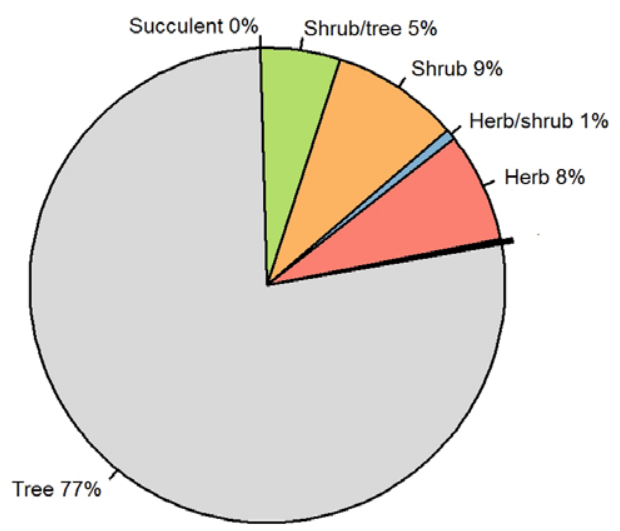

(f) NM species

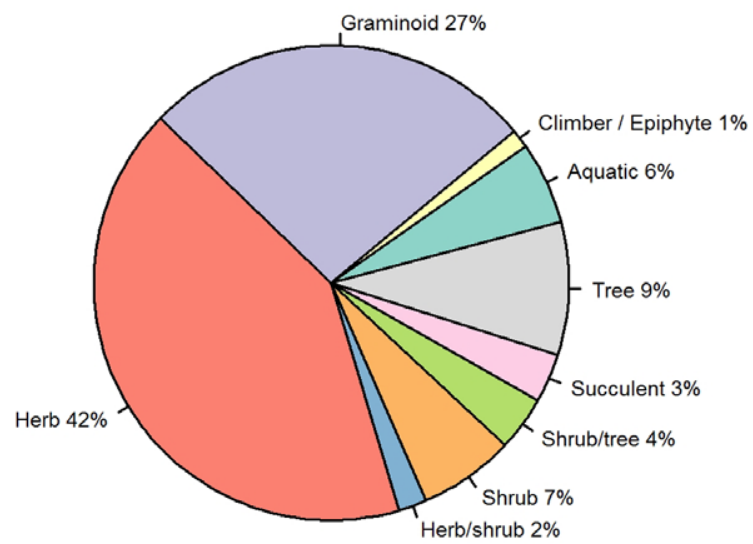

Fig. 4 Distribution of plant growth form types across the main mycorrhizal types: (a) obligate arbuscular mycorrhizal (AM) plant species; (b) facultative AM plant species; (c) plant species featuring double (ectomycorrhizal (EcM) and AM) colonization; (d) EcM plant species; (e) ericoid mycorrhizal (ErM) plant species; (f) nonmycorrhizal (NM) plant species.

distributed across the other plant growth forms. Among facultatively AM (AM-NM) plants this ratio is $60: 10: 10: 20$. The great majority of ectomycorrhizal plants are trees and shrubs
(92\%) and most of ErM plants are shrubs (85\%). Among NM plant species, $70 \%$ are herbaceous plants, $10 \%$ are trees and $20 \%$ belong to other growth forms (Fig. 4). 
Finally, we examined the main patterns of variation in intensity of root colonization by mycorrhizal fungi. We calculated the coefficients of variation $(\mathrm{CV})$ of the colonization intensity data for the $10 \mathrm{AM}$ and $10 \mathrm{EcM}$ species that had the highest number of observations of colonization intensity (Table S4). In order to examine whether plants show more variability in colonization intensity levels at the high or lower values of colonization intensity, we examined the CVs of the data points with colonization values of $0-50 \%$ and colonization values of $51-100 \%$ for each species (Table 1). Arbuscular mycorrhizal plants tend to have higher levels of variation in colonization intensity, although this pattern was only marginally significant $(P=0.07$; Table 1$)$. Assessment of colonization intensity values within the low (0-50$\%$ ) and high (51-100\%) ranges of colonization intensity revealed that AM plants had higher CVs of colonization intensity than EcM plants $(P=0.04)$, only at low colonization intensity range. We also examined whether facultatively mycorrhizal plants had higher levels of variability in colonization intensity than obligately mycorrhizal plants. Due to the paucity of facultatively EcM plants, we conducted this assessment for AM plants only. We considered plants to be obligate AM if our database had $>10$ records for a plant species and all such records reported AM colonization $>0 \%$. For analysis consistency, we selected species that also had $>10$ records and AM colonization intensity between $0 \%$ and $100 \%$. This pre-selection yielded 79 obligate AM species and 67 facultative ones. For each species we calculated the CV of colonization intensity and subjected these CVs to one-way ANOVA. This analysis indicated that facultative AM plant species have much higher variability in colonization level than obligate mycorrhizal $(0.73 \pm 0.04$ vs $0.31 \pm 0.02$, mean $\pm \mathrm{SE}$, $\left.P<0.001, F_{1,144}=77.8\right)$.

\section{Discussion}

The FungalRoot database presented here provides species-by-site information about plant mycorrhizal associations and

Table 1 Variability of colonization intensity levels across the 10 arbuscular mycorrhizal (AM) and 10 ectomycorrhizal (EcM) plant species that had highest number of colonization records in the database.

\begin{tabular}{lrrrr}
\hline Colonization type & Mean \pm SE & $P$-value & $F$-value & Residual df \\
\hline CV across the entire range of coloniation values & & \\
AM & $0.56 \pm 0.09$ & 0.07 & 3.73 & 18 \\
EcM & $0.35 \pm 0.05$ & & & \\
CV of values across the $0-50 \%$ colonization level & & \\
AM & $1.04 \pm 0.13$ & 0.04 & 5.18 & 14 \\
EcM & $0.62 \pm 0.12$ & & \\
CV of values across the $51-100 \%$ colonization level & \\
AM & $0.15 \pm 0.04$ & 1.69 & 0.21 & 17 \\
EcM & $0.29 \pm 0.1$ & &
\end{tabular}

$\mathrm{CV}$, coefficient of variation calculated for each species (1) across the entire range of colonization values exhibited by a species, (2) across low values of colonization (0-50\%), and (3) across higher levels of colonization (51$100 \%$ ). Mean values of per species of CV, their SEs, and outcomes of oneway ANOVAs examining variation between $\mathrm{AM}$ and EcM plants are shown. colonization intensity. Such data are urgently needed given the ultimate importance of such data for understanding functioning of terrestrial ecosystems. We have significantly advanced previous attempts of such data compilations by an exhaustive search for non-English literature, very old (> 60 years) and recent literature, which resulted in a tripling of the number of species compared with the previously largest mycorrhizal type checklists (e.g. Wang \& Qiu, 2006; Akhmetzhanova et al., 2012, Werner et al., 2018) that all contain records for approx. 3000 plant species (to a large extent overlapping).

The database enables summary of the contemporary information about the distribution of plant species per mycorrhizal type and distribution of mycorrhizal types per growth form. Our data confirm the earlier claims that the majority of mycorrhizal plants are arbuscular mycorrhizal (AM) (70\% in our dataset), whereas ectomycorrhizal (EcM) plants, despite being widely distributed (Read, 1991), constitute only a tiny fraction of all vascular plant species $(0.7 \%$ in our dataset). However, given the fact that our data represent the research efforts in mycorrhizal studies rather than the true distribution of mycorrhizal plant species, these numbers should be treated with caution. Our data suggest that only c. 5\% of all approx. 308312 vascular plant species (Christenhusz \& Byng, 2016) have been examined for mycorrhizal type, with tropical plants being particularly understudied. Thus, further research is needed to obtain a truly quantitative understanding of patterns of mycorrhizal type distributions among vascular plants.

Despite the generally accepted view that the majority of EcM and ericoid mycorrhizal (ErM) plants are shrubs and trees, whereas AM and nonmycorrhizal (NM) type are more or less equally distributed among plant growth forms, quantitative analyses on the distribution of plant mycorrhizal types among growth forms has not been conducted until now. The data shown in Fig. 3 constitute a first attempt at quantitative exploration of thus far available information about mycorrhizal types of plant growth forms. The question of what aspects of plant and mycorrhizal fungal physiology have led to the overwhelming prevalence of woody forms among EcM and ErM plants is particularly intriguing. Further ecophysiological analyses of growth form preferences among plant mycorrhizal types will allow spatial patterns of plant growth form distributions to be linked to mycorrhizal traits. Given that the majority of ecological models of regional and global vegetation distribution, and ecosystem functioning are based on plant growth forms, this information will advance our understanding of the impacts of mycorrhizas on the functioning of terrestrial ecosystems.

By providing detailed information about the intensity of mycorrhizal root colonization of plant species across multiple sites, our database enables advanced analyses of the intriguing patterns of variation in this, so far, poorly understood plant trait. We detected that levels of ectomycorrhizal colonization exhibited lower variability than levels of AM colonization, especially in the lower range of colonization values (Tables 1, S4). Furthermore, our analyses suggest that obligate vs facultative habit of mycorrhizal colonization strongly affects variation in intensity of root mycorrhizal colonization, with 
facultatively mycorrhizal plants having twice as large variation.

Erroneous mycorrhizal diagnoses, often provided in old literature, and their blind, uncritical use have resulted in biased or incorrect interpretations of effects of mycorrhizal types on evolutionary, biogeographic and ecophysiological processes. To overcome these issues, we compared the original records with expert opinions derived from the rest of the data and other publications to construct a recommendation list for plant mycorrhizal associations (Table S2). It must, however, be noted that using this list uncritically has the following limitations: (1) it provides insufficient information about individual species and the effect of edaphic and climatic effects on mycorrhizal status; and (2) it may offer erroneous assignments to facultatively mycorrhizal taxa in ecosystems that are early successional, or exhibit extreme levels of nutrients or climatic conditions, such as alpine, flooded or fertilized habitats. In such cases, we recommend considering specieslevel assignments, provided in the FungalRoot database, accompanied by edaphic data from specific regions or biomes, available as metadata in the FungalRoot database. For species and genera not covered in the FungalRoot database, we strongly recommend in situ determination of mycorrhizal types and mycorrhizal colonization.

In conclusion, the FungalRoot database features a number of unique characteristics, which will enrich the possibilities of scientific research based on the compiled metadata about locality, biome and edaphic conditions of the plant root sampling points. Such data enable quantitative analyses of drivers of mycorrhizal fungal colonization and distribution of mycorrhizal types, which are vital to help understand the impacts of mycorrhizal symbiosis on functioning of the human-affected ecosystems. Furthermore, the database records have been traced to original publications, which enabled us to eliminate duplicated records caused by combining information from multiple compilations. The thorough quality-check of the of mycorrhizal type data in the database, alongside the recommendations for the genus-level mycorrhizal colonization-type assignments (Table S2), have the potential to considerably reduce errors in scientific studies addressing mycorrhizal type effects. Therefore, our database can be readily used to assess the ecophysiological roles of mycorrhizal types in plant communities and ecosystem services and in comparative phylogenetics analyses targeting trait evolution. When coupled to other plant trait, ecological, evolutionary, soil and climate data, the FungalRoot database enables testing large-scale hypotheses about global processes, such as biogeochemical nutrient cycling, climate change impact, and the co-evolution of plants and fungi.

\section{Acknowledgements}

LT received funding from the Estonian Science Foundation (PUT1399, MOBERC). NS, MB,SFG and SV were supported by the vidi grant 016.161 .318 provided by the Netherlands Organization for scientific research (NWO), issued to NS.

\section{Author contributions}

NAS and LT planned and designed research and wrote the first draft of the manuscript; NS, LH, SV, MB, SR, MCB and JH performed the literature search and assembled the database; MCB, SG and VM contributed the data; LT and MCB enabled the data quality check; KA enabled embedment of the database into the PlutoF work-bench. All authors contributed to the manuscript writing and editing. NAS and LT contributed equally to this work. SV and MB contributed equally to this work, being the main data compilers.

\section{ORCID}

Kessy Abarenkov (ID https://orcid.org/0000-0001-5526-4845 Milagros Barcelo (DD https://orcid.org/0000-0003-0454-629X

Mark C. Brundrett (ID https://orcid.org/0000-0002-2501-9037

Sofia I.F. Gomes (D) https://orcid.org/0000-0001-7218-1531

Vincent Merckx (iD https://orcid.org/0000-0002-3959-8623

Saleh Rahimlou (D) https://orcid.org/0000-0003-0427-1329

Nadejda A. Soudzilovskaia (D) https://orcid.org/0000-0002-

9584-2109

Leho Tedersoo (iD https://orcid.org/0000-0002-1635-1249

Stijn Vaessen (iD https://orcid.org/0000-0002-4481-6656

\section{References}

Abarenkov K, Henrik Nilsson R, Larsson KH, Alexander IJ, Eberhardt U, Erland S, Høiland K, Kjøller R, Larsson E, Pennanen T. 2010a. The UNITE database for molecular identification of fungi-recent updates and future perspectives. New Phytologist 186: 281-285.

Abarenkov K, Tedersoo L, Nilsson RH, Vellak K, Saar I, Veldre V, Parmasto E, Prous M, Aan A, Ots M. 2010b. PlutoF-a web based workbench for ecological and taxonomic research, with an online implementation for fungal ITS sequences. Evolutionary Bioinformatics 6: EBO.S6271.

Akhmetzhanova AA, Soudzilovskaia NA, Onipchenko VG, Cornwell WK, Agafonov VK, Selivanov IA, Cornelissen JHC. 2012. A rediscovered treasure: mycorrhizal intensity database for 3000 vascular plants species across the former Soviet Union. Ecology 93: 689-690.

Averill C, Hawkes CV. 2016. Ectomycorrhizal fungi slow soil carbon cycling. Ecology Letters 19: 937-947.

Brundrett M. 2009. Mycorrhizal associations and other means of nutrition of vascular plants: understanding the global diversity of host plants by resolving conflicting information and developing reliable means of diagnosis. Plant and Soil 320: 37-77.

Brundrett M. 2017. Global diversity and importance of mycorrhizal and nonmycorrhizal plants. In: Tedersoo L, ed. Biogeography of mycorrhizal symbiosis. Cham, Switzerland: Springer International: 533-556.

Brundrett M, Tedersoo L. 2018. Evolutionary history of mycorrhizal symbioses and global host plant diversity. New Phytologist 220: 11081115

Brundrett M, Tedersoo L. 2019. Misdiagnosis of mycorrhizas and inappropriate recycling of data can lead to false conclusions. New Phytologist 221: 18-24.

Bueno C, Aldrich-Wolfe L, Chaudhary VB, Gerz M, Helgason T, Hoeksema JD, Klironomos J, Lekberg Y, Hafiz DL, Öpik MM et al. 2019. Misdiagnosis and uncritical use of plant mycorrhizal data are not the only elephants in the room. New Phytologist 224: 1415-1418.

Christenhusz MJM, Byng JW. 2016. The number of known plants species in the world and its annual increase. Phytotaxa 261: 201-217. 
Cornelissen JHC, Aerts R, Cerabolini B, Werger MJA, van der Heijden MGA. 2001. Carbon cycling traits of plant species are linked with mycorrhizal strategy. Oecologia 129: 611-619.

Delaux P-M, Varala K, Edger PP, Coruzzi GM, Pires JC, Ané J-M. 2014. Comparative phylogenomics uncovers the impact of symbiotic associations on host genome evolution. PLoS Genetics 10: 1004487.

Elumeeva TG, Onipchenko VG, Cornelissen JH, Semenova GV, Perevedentseva LG, Freschet GT, van Logtestijn RS, Soudzilovskaia NA. 2018. Is intensity of plant root mycorrhizal colonization a good proxy for plant growth rate, dominance and decomposition in nutrient poor conditions? Journal of Vegetation Science 29: 715-725

Gerz M, Bueno CG, Zobel M, Moora M. 2016. Plant community mycorrhization in temperate forests and grasslands: relations with edaphic properties and plant diversity. Journal of Vegetation Science 27: 89-99.

Harley JL, Harley E. 1987. A check-list of mycorrhiza in the British flora. New Phytologist 105: 1-102.

van der Heijden MGA, Klironomos JN, Ursic M, Moutoglis P, Streitwolf-Engel R, Boller T, Wiemken A, Sanders IR. 1998. Mycorrhizal fungal diversity determines plant biodiversity, ecosystem variability and productivity. Nature 396: 69-72.

Hempel S, Gotzenberger L, Kuhn I, Michalski SG, Rillig MC, Zobel M, Moora M. 2013. Mycorrhizas in the Central European flora - relationship with plant life history traits and ecology. Ecology 94: 1389-1399.

Hoeksema J, Bever J, Chakraborty S, Chaudhary V, Gardes M, Gehring C, Hart M, Housworth E, Kaonongbua W, Klironomos J et al. 2018. Evolutionary history of plant hosts and fungal symbionts predicts the strength of mycorrhizal mutualism. Communication Biology 1: 116.

Hoeksema JD, Chaudhary VB, Gehring CA, Johnson NC, Karst J, Koide RT, Pringle A, Zabinski C, Bever JD, Moore JC et al. 2010. A meta-analysis of context-dependency in plant response to inoculation with mycorrhizal fungi. Ecology Letters 13: 394-407.

Imhof S, Massicote HB, Melville LH, Petereson RL. 2013. Subterranean morphology and mycorrhizal structures. In: Merckx V, ed. Mycoheterotrophy. New York, NY, USA: Springer International: 157-214.

Karst J, Marczak L, Jones MD, Turkington R. 2008. The mutualism-parasitism continuum in ectomycorrhizas: a quantitative assessment using meta-analysis. Ecology 89: 1032-1042.

Kattge J, Diaz S, Lavorel S, Prentice C, Leadley P, Bonisch G, Garnier E, Westoby M, Reich PB, Wright IJ et al. 2011. TRY - a global database of plant traits. Global Change Biology 17: 2905-2935.

Klironomos J. 2000. Host-specificity and functional diversity among arbuscular mycorrhizal fungi. Microbial Biosystems 1: 845-851.

Klironomos JN, McCune J, Hart M, Neville J. 2000. The influence of arbuscular mycorrhizae on the relationship between plant diversity and productivity. Ecology Letters 3: 137-141.

Klironomos J, Zobel M, Tibbett M, Stock WD, Rillig MC, Parrent JL, Moora M, Koch AM, Facelli JM, Facelli E et al. 2011. Forces that structure plant communities: quantifying the importance of the mycorrhizal symbiosis. New Phytologist 189: 366-370.

Koele N, Dickie IA, Oleksyn J, Richardson SJ, Reich PB. 2012. No globally consistent effect of ectomycorrhizal status on foliar traits. New Phytologist 196 845-852.

Kohout P. 2017. Biogeography of ericoid mycorrhiza. In: Tedersoo L, ed. Biogeography of mycorrhizal symbiosis. Cham, Switzerland: Springer, 179193.

Leake JR, Johnson D, Donnelly DP, Muckle GE, Boddy L, Read DJ. 2004. Networks of power and influence: the role of mycorrhizal mycelium in controlling plant communities and agroecosystem functioning. Canadian Journal of Botany-Revue Canadienne De Botanique 82: 1016-1045.

Maltz MR, Treseder KK. 2015. Sources of inocula influence mycorrhizal colonization of plants in restoration projects: a meta-analysis. Restoration Ecology 23: 625-634.

Merckx VS. 2013. Mycoheterotrophy: an introduction. In: Merckx V, ed. Mycoheterotrophy. New York, NY, USA: Springer, 1-17.

Phillips RP, Brzostek E, Midgley MG. 2013. The mycorrhizal-associated nutrient economy: a new framework for predicting carbon-nutrient couplings in temperate forests. New Phytologist 199: 41-51.
Read DJ. 1991. Mycorrhizas in ecosystems. Experientia 47: 376-391.

Schneider-Maunoury L, Deveau A, Moreno M, Todesco F, Belmondo S, Murat C, Courty PE, Jąkalski M, Selosse MA. 2020. Two ectomycorrhizal truffles, Tuber melanosporum and T. aestivum, endophytically colonize roots of nonectomycorrhizal plants in natural environments. New Phytologist. 225: 2542 2556.

Smith SE, Read DJ. 2008. Mycorrhizal symbiosis. London, UK: Academic Press. Soudzilovskaia NA, Douma JC, Akhmetzhanova AA, van Bodegom PM, Cornwell WK, Moens EJ, Treseder KK, Tibbett M, Wang YP, Cornelissen JHC. 2015b. Global patterns of plant root colonization intensity by mycorrhizal fungi explained by climate and soil chemistry. Global Ecology and Biogeography 24: 371-382.

Soudzilovskaia NA, Heijden MGA, Cornelissen JHC, Makarov MI, Onipchenko VG, Maslov MN, Akhmetzhanova AA, Bodegom PM. 2015a. Quantitative assessment of the differential impacts of arbuscular and ectomycorrhiza on soil carbon cycling. New Phytologist 208: 280-293.

Sun T, Zhang H, Wang Z. 2019. Reply to Tedersoo et al:: Plant species within the same family or genus can have different mycorrhizal types? Proceedings of the National Academy of Sciences, USA 116: 12141-12142.

Tedersoo L. 2017. Global biogeography and invasions of ectomycorrhizal plants: past, present and future. In: Tedersoo L, ed. Biogeography of mycorrhizal symbiosis. Cham, Switzerland: Springer, 469-531.

Tedersoo L, Bahram M. 2019. Mycorrhizal types differ in ecophysiology and alter plant nutrition and soil processes. Biological Reviews 94: 1857-1880.

Tedersoo L, Brundrett M. 2017. Evolution of ectomycorrhizal symbiosis in plants. In: Tedersoo L, ed. Biogeography of mycorrhizal symbiosis. Cham, Switzerland: Springer, 407-467.

Tedersoo L, Rahimlou S, Brundrett M. 2019. Misallocation of mycorrhizal traits leads to misleading results. Proceedings of the National Academy of Sciences, USA 116: 12139-12140.

Terrer C, Vicca S, Hungate BA, Phillips RP, Prentice IC. 2016. Mycorrhizal association as a primary control of the $\mathrm{CO}_{2}$ fertilization effect. Science 353 : $72-74$.

Treseder KK. 2013. The extent of mycorrhizal colonization of roots and its influence on plant growth and phosphorus content. Plant and Soil 371: $1-13$.

Veresoglou SD, Chen BD, Rillig MC. 2012a. Arbuscular mycorrhiza and soil nitrogen cycling. Soil Biology \& Biochemistry 46: 53-62.

Veresoglou SD, Menexes G, Rillig MC. 2012b. Do arbuscular mycorrhizal fungi affect the allometric partition of host plant biomass to shoots and roots? A meta-analysis of studies from 1990 to 2010. Mycorrhiza 22: 227-235.

Wang B, Qiu YL. 2006. Phylogenetic distribution and evolution of mycorrhizas in land plants. Mycorrhiza 16: 299-363.

Werner GD, Cornelissen JH, Cornwell WK, Soudzilovskaia NA, Kattge J, West SA, Kiers ET. 2018. Symbiont switching and alternative resource acquisition strategies drive mutualism breakdown. Proceedings of the National Academy of Sciences 115: 5229-5234.

\section{Supporting Information}

Additional Supporting Information may be found online in the Supporting Information section at the end of the article.

Fig. S1 Plant species that have highest number of records $(>40)$ in the FungalRoot database.

Notes S1 Introduction to the use of PlutoF.

Table S1 Description of FungalRoot database fields.

Table S2 Recommended mycorrhizal status for plant genera, based on $\geq 67 \%$ consistency of species diagnosis for a given mycorrhizal type. It is a large EXCEL file submitted separately. 
Table S3 Families not included in studies of mycorrhizal associations. It is a large ExCEL file submitted separately.

Table S4 Coefficients of variation (CV) of colonization intensity data for the $10 \mathrm{AM}$ and $10 \mathrm{EcM}$ species that have the highest number of observations of colonization intensity in the FungalRoot database.
Please note: Wiley Blackwell are not responsible for the content or functionality of any Supporting Information supplied by the authors. Any queries (other than missing material) should be directed to the New Phytologist Central Office.

\section{About New Phytologist}

- New Phytologist is an electronic (online-only) journal owned by the New Phytologist Trust, a not-for-profit organization dedicated to the promotion of plant science, facilitating projects from symposia to free access for our Tansley reviews and Tansley insights.

- Regular papers, Letters, Research reviews, Rapid reports and both Modelling/Theory and Methods papers are encouraged. We are committed to rapid processing, from online submission through to publication 'as ready' via Early View - our average time to decision is $<26$ days. There are no page or colour charges and a PDF version will be provided for each article.

- The journal is available online at Wiley Online Library. Visit www.newphytologist.com to search the articles and register for table of contents email alerts.

- If you have any questions, do get in touch with Central Office (np-centraloffice@lancaster.ac.uk) or, if it is more convenient, our USA Office (np-usaoffice@lancaster.ac.uk)

- For submission instructions, subscription and all the latest information visit www.newphytologist.com 